Supporting Information

\title{
Fe(III) Coordination Chemistry of Alterobactin A: A Siderophore from the Marine Bacterium Alteromonas luteoviolacea
}

Pamela D. Holt ${ }^{1, \perp}$, Richard R. Reid ${ }^{1,},{ }^{\xi}$, Brent L. Lewis ${ }^{2}{ }$, George W. Luther III ${ }^{2}$, Alison

$$
\text { Butler }^{1} *
$$

${ }^{1}$ Department of Chemistry and Biochemistry

University of California

Santa Barbara, CA 93106-9510

\&

${ }^{2}$ College of Marine Studies

University of Delaware

Lewes, DE 19958

* To whom correspondence should be addressed Butler@chem.ucsb.edu 
Figure S-1. A Job's plot of continuous variations for Fe(III)-(Alt-A). The maximum at 0.5 mole ratio corresponds to a 1:1 complex for Fe(III)-(Alt-A).

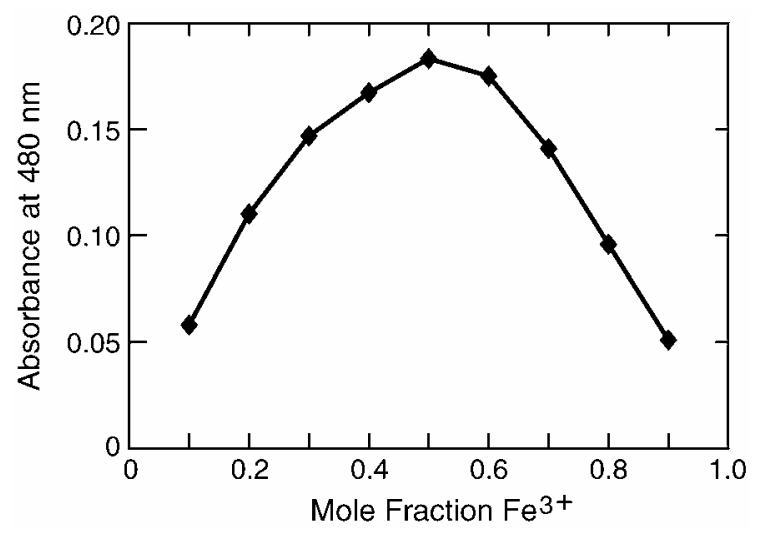

Figure S-2. UV-Visible spectra of Fe(III)-(Alt-A) vs pH. Conditions: $0.2 \mathrm{mM} \mathrm{Fe(III)-}$ (Alt-A), $100 \mathrm{mM} \mathrm{KNO}$. The $\mathrm{pH}$ was adjusted by addition of $5 \mu \mathrm{L}$ aliquots of a $40 \mathrm{mM}$ $\mathrm{NaOH}$ solution. Curves are from the bottom up at $\mathrm{pH}$ : 4.14; 4.42; 4.91; 6.15; 6.42; 6.91; $7.16 ; 7.65 ; 7.99 ; 8.84$.

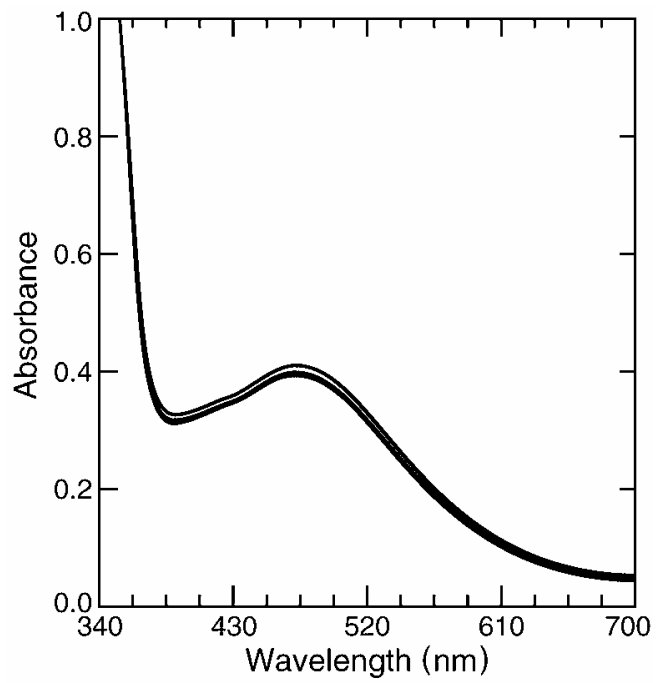

